\section{Questión}

Periodismo / Comunicación

ISSN 1669-6581

Discursos mediáticos sobre derechos de migrantes, desde los DDHH

Laura Angélica Gottero

Question/Cuestión, Vol. 2, №66, Agosto 2020

ISSNe 1669-6581

https://perio.unlp.edu.ar/ojs/index.php/question/index

IICom-FPyCS-UNLP

DOI: $\underline{\text { https//doi.org/10.24215/16696581e477 }}$

\title{
Discursos mediáticos sobre derechos de migrantes, desde los ddhh
}

\section{Media discourses on migrant rights, from human rights}

Laura Angélica Gottero Instituto de Justicia y Derechos Humanos, Universidad Nacional de Lanús, Argentina

lauritagottero@gmail.com https://orcid.org/0000-0002-3912-644X

\section{Resumen}

El artículo focaliza en las posibilidades metodológicas de las ciencias de la comunicación para estudiar el acceso a derechos para personas migrantes tematizado en los discursos mediáticos, pues esta construcción simbólica incide en sus posibilidades concretas de protección y respeto en las sociedades donde se encuentran. 
La finalidad de esta investigación es aportar razonamientos e insumos para pensar un modelo de comunicación con base en el enfoque de derechos que permita proteger y reconocer el acceso a derechos de personas migrantes no sólo en el contexto de los discursos mediáticos, sino en el plano donde éstos inciden de manera clara: las prácticas sociales en sus diversas expresiones.

\title{
Palabras clave
}

Discurso mediático, Enfoque de derechos humanos, Migraciones, Periodismo.

\begin{abstract}
Study the access to rights for migrants themed in media speeches, since this symbolic construction affects their concrete possibilities of protection and respect in the societies where they are located.

The purpose of this research is to provide reasoning and inputs to think about a communication model based on the rights approach that allows protecting and recognizing the access to rights of migrants not only in the context of media discourses, but at the level where These clearly influence: social practices in their various expressions.
\end{abstract}

\section{Key Words}

Media discourse, Human right s approach, Migration, Journalism.

Las ciencias de la comunicación se han constituido como un campo interdisciplinario de conocimiento, donde han abrevado conceptos y herramientas metodológicas de las ciencias humanísticas y sociales, en 
articulación con la constitución, actualización y debate de teorías comunicacionales surgidas de los procesos de indagación propios de esta disciplina.

En el periodo reciente, este campo disciplinar se ha revelado sumamente fructífero para construir aportes al estudio de las migraciones, enlazando sus modos de investigación con el análisis del fenómeno migratorio en los contextos sociales donde se desenvuelve. De esta manera, puede dar cuenta con teorías y metodologías del campo comunicacional cómo se producen representaciones de las personas migrantes y de la movilidad humana en las esferas mediáticas, políticas, sociales e institucionales, creando así discursos que se ponen en circulación y se retroalimentan, logrando efectos concretos en diversos escenarios. En consecuencia, estas experiencias de investigación lograron evidenciar la influencia que ejercen diferentes planteos comunicacionales (mediáticos y no mediáticos) sobre la migración y sus protagonistas, la que incide claramente en las características de la interacción social entre migrantes y no migrantes en sociedades de recepción y, más ampliamente, cómo se organiza la discusión sobre el modo y grado de acceso a derechos de quienes migran en sus espacios de tránsito y destino.

La articulación entre investigaciones comunicacionales, estudios de migraciones y perspectivas de derechos humanos se revela especialmente necesaria en la actualidad, a partir de las dinámicas de retroceso en materia de reconocimiento y garantía de derechos para personas migrantes en el orden global, que se manifiestan en el periodo reciente. Esta vinculación disciplinar constituye un área de construcción incipiente aún, en tanto los abordajes de los derechos humanos han sido tradicionalmente construidos desde el derecho, la historia, pero las ciencias de la comunicación presentan un marco conceptual y 
metodológico de relevancia para construir aportes en este sentido. De allí que pensar ciertas «entradas» desde la comunicación y los derechos humanos para el abordaje de las migraciones en/y los medios de comunicación sea el objetivo de este artículo.

\section{Pensar el acceso a derechos de migrantes, desde la comunicación y los derechos humanos}

Este trabajo pretende focalizar en las posibilidades metodológicas propias de las ciencias de la comunicación para estudiar el acceso a derechos para personas migrantes, el que se construye simbólicamente (o se obstruye) desde la producción, difusión y retroalimentación de discursos mediáticos. En este trabajo, el foco estará puesto en el empleo de la estrategia metodológica de análisis del discurso con un enfoque comunicacional -no exclusivamente lingüístico-, puesto que esta modalidad de indagación resulta una de las más utilizadas formal o informalmente para estudiar discursos producidos por los medios. Y el abordaje discursivo de las producciones mediáticas permitirá «poner texto en contexto»-pensando en una definición coloquial de discurso-, con lo cual el camino hacia la caracterización de las representaciones sobre el acceso a derechos de migrantes se encuentra allanado, y en este punto es donde la perspectiva de derechos humanos como propuesta conceptual y metodológica puede fortalecer el carácter transdisciplinario de la comunicación, a la vez de ofrecer insumos claros y concretos para incorporar esta dimensión en las políticas públicas que gestionan y regulan el acceso a derechos de personas migrantes. 


\section{Los discursos mediáticos sobre migración como base de una discusión de DDHH}

La labor mediática y periodística constituye una vía concreta para activar y desactivar prejuicios y estereotipos respecto de grupos sociales; en consecuencia, posee un enorme potencial en términos de generar debates en la sociedad que tiendan al desarme o a la cristalización de representaciones e imágenes consolidadas por efecto del tiempo y de la naturalización de estigmatizaciones históricas. En relación con las personas migrantes, un abordaje mediático con enfoque de derechos permite visibilizar las obligaciones del Estado para con ese grupo, permite construir a sus integrantes como sujetos de derechos en condición de igualdad, y además contribuye a reenfocar la producción de información mediática evaluando nuevamente el núcleo de la noticia y la manera de dar cuenta de los hechos.

Desde el lado de la investigación en comunicación, estos mismos parámetros se pueden adaptar al estudio de los discursos mediáticos sobre personas migrantes en relación con su potencial o su alcance efectivo en materia de, primero, un reconocimiento del derecho a la comunicación como derecho humano - centralizado en el grupo migrante- y, segundo, de la conciencia paulatina de la incidencia en materia de derechos que ciertos discursos pueden efectuar, sobre todo desde un análisis de igualdad y no discriminación. Es por eso que una combinación adecuada de análisis comunicacionales del discurso y el enfoque de derechos humanos, aplicada al estudio de los fenómenos migratorios, puede ofrecer resultados fructíferos a los avances de investigación sobre derechos de migrantes en contextos específicos, a la vez que permite revisar y actualizar las discusiones sobre el rol y las dinámicas mediáticas en el orden nacional, provincial o local. 
Siguiendo la identificación de estas potencialidades, puede afirmarse que la presencia de las migraciones y las movilidades en relación con la comunicación y los medios se da a través de dos grandes vías: a) migración/migrantes como sujetos de la comunicación; b) migración/migrantes como objetos de la comunicación. Ambas dimensiones confluyen en el desafío de pensar contextualmente a la comunicación mediática y sus actores en escenarios de migración, articulando estas reflexiones con la perspectiva de derechos.

\section{a. Migración/migrantes como sujetos de la comunicación}

Esta vía de análisis enfoca los alcances y obstáculos que posee el grupo social de migrantes para realizar acciones autónomas e igualitarias de expresión y comunicación en diversos ámbitos: mediáticos, políticos, educativos, organizacionales, gremiales, etc. Si bien ese eje suele focalizarse en la posibilidad efectiva que tienen las/os migrantes para acceder a la producción y difusión de mensajes mediáticos de su interés -en medios masivos, alternativos, comerciales o comunitarios-, también puede pensarse que la consolidación política e institucional de la figura de las personas migrantes como un grupo que tiene necesidades específicas en el ejercicio de la comunicación mediática, también contribuye a indagar su situación como sujetos de derechos también cuando los discursos no sean producidos por ellos/as mismos/as, a través del análisis e identificación de formas de interpelación, caracterización y elaboración de representaciones sociomediáticas (Melella, 2015; Gottero, 2010).

El acceso al derecho a la comunicación se encuentra configurado mediante normativas internacionales de derechos humanos, así también por normas nacionales relativas a la gestión y regulación del sistema de medios en cada 
país. En el caso argentino, el estado de la cuestión normativa en relación con el derecho a la comunicación ha sido profundamente indagado por diversos autores/as (Loreti, AÑO; Fraiman, 2015; Uranga, 2015; Lozano y Loreti, 2015) y no será objeto de esta ponencia. Pero para los objetivos de pensar una metodología desde la comunicación para el estudio de las formas de producir discursos mediáticos sobre las migraciones, sí resulta imprescindible hacer un punteo de los instrumentos de derechos humanos vinculados con el tema:

\begin{tabular}{|c|c|c|}
\hline $\begin{array}{l}\text { Sistema } \\
\text { Internacional de } \\
\text { DDHH }\end{array}$ & $\begin{array}{l}\text { Sistema } \\
\text { Interamericano } \\
\text { DDHH }\end{array}$ & $\begin{array}{l}\text { Otros antecedentes } \\
\text { internacionales } \\
\text { regionales }\end{array}$ \\
\hline 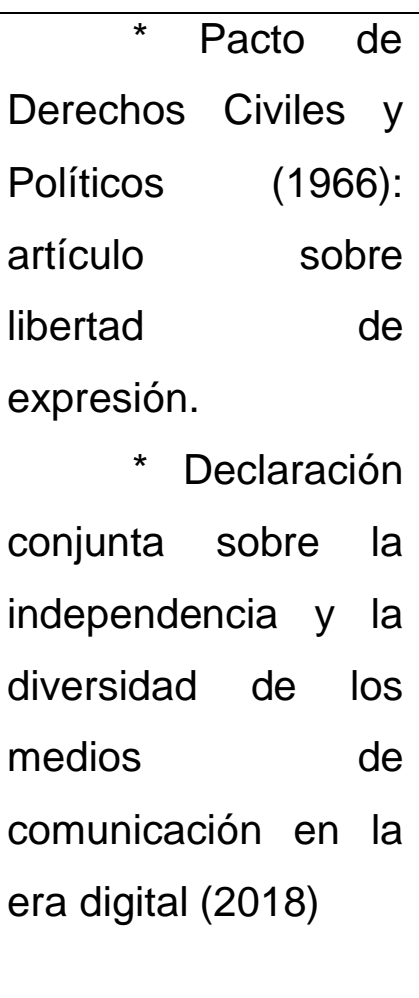 & $\begin{array}{l}\text { * Pacto de San } \\
\text { José de Costa Rica } \\
\text { (1969): artículos sobre } \\
\text { libertad de expresión, } \\
\text { así como derecho de } \\
\text { rectificación } \\
\text { respuesta. } \\
\text { * Declaración de } \\
\text { Libertad de Expresión } \\
\text { (2000) * Declaración } \\
\text { Conjunta sobre Libertad } \\
\text { de Expresión e Internet } \\
\text { (2011) }\end{array}$ & 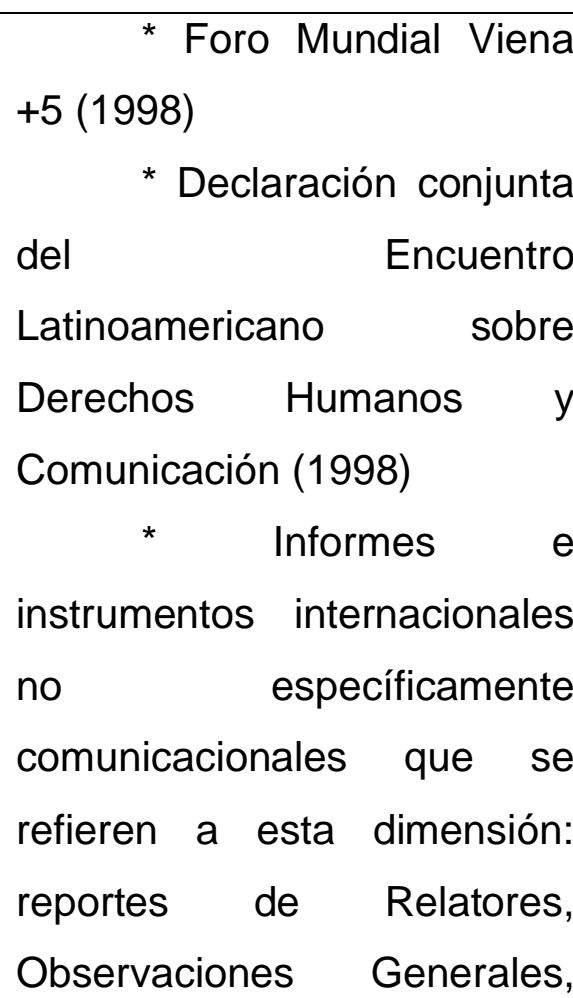 \\
\hline
\end{tabular}




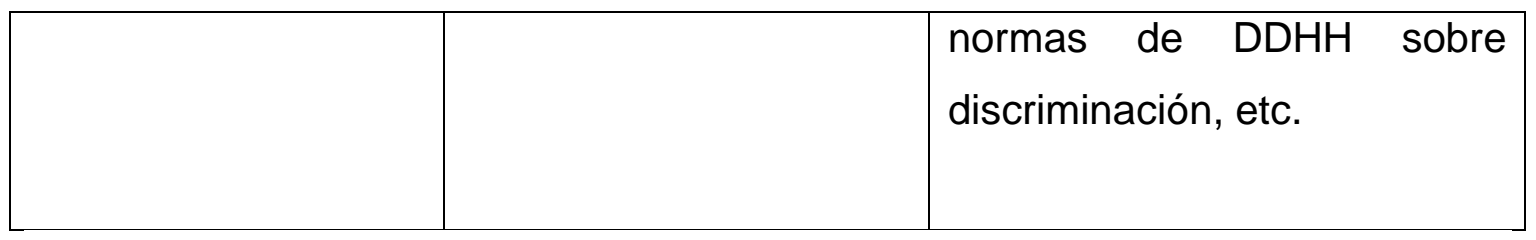

Tabla 1. Principales instrumentos de DDHH vinculados con el derecho a la comunicación. Fuente: elaboración propia.

En tanto los medios de comunicación mantienen una relación constante con el Estado a través de ser de orden público o bien de orden privado cuyo ejercicio está habilitado y regulado mediante la obtención de una licencia provista por el Estado, así también de una normativa que establece alcances y obligaciones de su ejercicio mediático, toda actividad de los medios puede ser estudiada desde un enfoque de derechos humanos. Ello implica, en principio, caracterizar la relación entre el Estado y ese medio en particular, contextualizando ésta en el panorama mediático general, ya sea de orden nacional, provincial o local. Luego, requiere de la observación de los mecanismos por los cuáles el aparato estatal protege a las audiencias de vulneraciones mediáticas de los derechos humanos, a través de la implementación de las normativas específicas y transversales sobre el tema. En el caso argentino, para el periodo actual, la norma específica que permite la vinculación de la actividad mediática con una perspectiva de derechos humanos y la consecuente responsabilidad del Estado, es el relevamiento acerca del cumplimiento de la Ley de Servicios de Comunicación Audiovisual ( $N^{\circ}$ 26.522), proceso que resulta materia de estudio de diversas investigaciones en la actualidad (Hernández Prieto y Pérez Alaejos, 2017; Komissarov, 2016; Loreti, 2010, Becerra y Mastrini, 2009; entre otros/as). En cuanto a las normas transversales que deben ser tenidas en cuenta, en cuanto a Argentina pueden citarse todas aquéllas que inciden en las 
garantías de las personas contra las múltiples formas de discriminación y violencia simbólica de origen mediático: por ejemplo, la Ley sobre actos discriminatorios (23.592/88), la Ley de protección integral para prevenir, sancionar y erradicar la violencia contra las mujeres en los ámbitos en que desarrollen sus relaciones interpersonales (26485/09), y como una norma no excluyente de las citadas pero que es específica del tema tratado en esta ponencia, la Ley de Migraciones (25871/03), que en sus artículos $4^{\circ}$ a $6^{\circ}$ establecen que el trato hacia los/as migrantes desde el Estado argentino se organizará sobre los principios de igualdad y no discriminación, garantizando el acceso igualitario a bienes y servicios comunes ${ }^{1}$.

Todo este entramado normativo internacional, regional y nacional puede ser analizado con metodologías propias del campo de la comunicación -a partir de las herramientas provistas por el ámbito del derecho a la comunicación y del análisis del discurso aplicado a las producciones mediáticas, entre otras opciones-, pero para incluir efectivamente una perspectiva de derechos se requieren metodologías específicas que vinculen esta labor de análisis con guías especialmente diseñadas desde el campo de los derechos humanos. Es así como la incorporación de una indagación a partir de los modelos de estudio de políticas públicas y el accionar efectivo del Estado a partir del enfoque de derechos humanos se revelan como herramientas conceptuales y metodológicas propicias para caracterizar y evaluar estos procesos.

Tal como señalan Julieta Rossi y Javier Moro (2014), en la actualidad existen dos modelos preponderantes para el diseño de políticas públicas con perspectiva de derechos humanos: la propuesta esbozada por Naciones Unidas (2006), y la guía metodológica-conceptual desarrollada por la Organización de Estados Americanos (OEA) entre 2008 y 2015. 
Con respecto a esta última, su elaboración surge del contenido del Protocolo de San Salvador (1998), puntapié para el diseño de la metodología específica del enfoque de derechos humanos para la formulación, implementación y evaluación de políticas públicas en el ámbito interamericano. Dicho desarrollo fue plasmado en el documento Indicadores de progreso para medición de derechos contemplados en el Protocolo de San Salvador (OEA, 2015), que explica el modo de identificación y evaluación de las obligaciones estatales incluidas en la formulación de políticas. Esta propuesta, de carácter vinculante para los Estados que aprobaron el Protocolo, se compone de indicadores cuantitativos y cualitativos: Ios primeros expresan un resultado esperado con magnitudes («cantidad de medios comunitarios o comerciales que son gestionados por colectividades migrantes, en relación con el total de medios del mismo tipo"), y los segundos caracterizan ese resultado esperado a través de dimensiones no mensurables («existencia y características de instancias de capacitación mediática para colectividades migrantes que pretenden organizar y desarrollar un medio de comunicación para su comunidad»).

Como elemento diferencial de esta propuesta, se propone la incorporación de señales de progreso que permitan indagar la experiencia que las personas consideran tener respecto de su acceso a derechos, y aquí es donde se observa el gran potencial que un modelo de estas características puede ofrecer para el estudio de las percepciones y posicionamientos subjetivos de las personas como sujetos de derecho a la comunicación, sobre todo si se tienen en cuenta las dimensiones temáticas que completa con contenidos específicos los indicadores y las señales. En efecto, éstos se indagan desde ejes transversales: igualdad y no discriminación, acceso a la información y participación, y acceso a la justicia que, en el caso del ejercicio de la 
comunicación, permitirían caracterizar en profundidad la vinculación entre las audiencias (haciendo foco en el colectivo migrante, en este caso), el Estado y los medios de comunicación.

Asimismo, el análisis desde el enfoque de derechos de acuerdo con esta metodología incluye la observación de otros tres aspectos: recepción del derecho (forma en que un derecho del Protocolo se encuentra incorporado en la normativa nacional y las políticas públicas), contexto financiero y presupuestario (disponibilidad efectiva de recursos para la ejecución de políticas públicas), y capacidades estatales e institucionales (de qué manera el Estado establece y sostiene agencias específicas para la implementación de políticas públicas, donde confluyan la recepción del derecho y el presupuesto necesario en pos de la provisión de los recursos humanos y materiales necesarios para la protección del derecho en cuestión). Aunque por razones de extensión sea imposible ofrecer un ejemplo práctico de análisis, resulta muy claro pensar el modo de estudiar procesos de derecho a la comunicación, discursos mediáticos y representación de las personas migrantes a partir de la puesta en práctica de este modelo metodológico de evaluación, y ello además constituye una instancia de trabajo actual de la que se desprende esta ponencia.

Por otra parte, y aplicada al ámbito global, la propuesta de Naciones Unidas no comprende un esquema con dimensiones y variables metodológicas, pero provee elementos para rastrear la incorporación del enfoque de derechos humanos en la acción del Estado, en relación estrecha con las estrategias gubernamentales orientadas al desarrollo. El planteo general no está orientado a visibilizar las obligaciones de los Estados en primer lugar, sino a persuadir del empleo del EDH en diferentes contextos nacionales apelando a diversos 
argumentos relacionados con la gestión pública. Así, este enfoque identifica a titulares de derechos y titulares de deberes como elemento característico — sin centrarse en la responsabilidad estatal como vértice del compromiso con los derechos humanos-, y establece como objetivo del EDH, en las políticas, la «realización» de los $\mathrm{DDHH}$.

La propuesta de la ONU no tematiza la dimensión de obligatoriedad sino la de conveniencia en el uso del EDH, al que se le asigna beneficios de orden práctico: a) clarificar derechos de «los más pobres entre los pobres»; b) lograr un abordaje holístico de los derechos humanos, como sustrato de políticas, mediante la referencia a los instrumentos internacionales de $\mathrm{DDHH}$; c) la posibilidad de generar procesos participativos; d) desarrollar mecanismos de transparencia y rendición de cuentas; e) concretar la vigilancia de los compromisos del Estado; e) exhibir resultados positivos sostenidos que hagan más efectivas «las inversiones». Si bien estos aspectos también pueden contribuir a caracterizar la situación de las personas migrantes en relación con los discursos mediáticos y su acceso efectivo al derecho a la comunicación, debe tenerse en cuenta que el esquema de ONU debilita las referencias a la responsabilidad estatal —núcleo de una evaluación desde los derechos humanos - para visibilizar una estrategia persuasiva pensada para efectivizar la adopción de estos fundamentos. Por último, la vinculación de la perspectiva de derechos humanos con los enfoques sobre el desarrollo otorga un carácter instrumental a aquélla, mostrándola como una herramienta favorable de gobierno, y no como una meta en sí misma².

La elección de una u otra opción para incorporar el enfoque de derechos humanos en las políticas públicas supone consecuencias importantes en el contenido y el alcance de la comunicación como derecho humano planificado 
que observa la situación particular de colectivos con necesidades específicas de acceso, como es el caso de las personas migrantes. De allí la necesidad de articular de manera equilibrada estas propuestas sin perder de vista la centralidad del Estado como actor protector y garante de derechos, planteando un diseño de investigación que parta de las siguientes preguntas:

\section{Elementos que conforman el contexto y el marco conceptual del abordaje} sobre medios y migrantes como sujetos del derecho a la comunicación:

a. Normativa nacional sobre sistemas de medios: ¿cómo están referidas (o no) las personas migrantes? ¿Cuáles son sus derechos y obligaciones en tanto sujetos de la comunicación? ¿Cuál es su relación con el marco normativo internacional de $\mathrm{DDHH}$ ?

b. Acceso concreto al derecho a la comunicación mediante la formulación de políticas públicas, así también por la provisión de recursos y espacios efectivos para el ejercicio mediático-comunicacional de los grupos menos favorecidos.

c. Diferenciación entre medios migrantes comerciales y medios migrantes comunitarios (que pueden tener pauta publicitaria pero no un único fin de lucro).

d. Inclusión (o no) de estas formas mediáticas específicas en políticas públicas de comunicación que visibilicen sus prácticas y necesidades específicas.

e. Formas de constitución (o no) de sujetos de la comunicación que surgen de grupos invisibilizados estructuralmente en su subjetividad mediática, pero que suelen estar hipervisibilizados como objetos mediáticos (ver sección siguiente).

Tabla 2. Dimensiones para tener en cuenta en el análisis de las representaciones sobre migrantes como sujetos de la comunicación. Fuente: elaboración propia. 


\section{b. Migración/migrantes como objetos de la comunicación}

De manera simultánea a las posibilidades metodológicas de indagar procesos comunicacionales mediáticos en relación con las personas migrantes consideradas como sujetos que ejercen su derecho a la comunicación, una dimensión inescindible de estas observaciones se orienta a la indagación del modo en que los discursos mediáticos representan a este grupo, así como las modalidades particulares en que éste puede manifestar su propia voz en los sucesos que se relatan en las noticias o productos de los diferentes medios. Sin pretensiones de generalizar, y sabiendo que cada afirmación requiere de un estudio pormenorizado sobre un corpus de materiales que haya sido justificado - puesto que ello constituye precisamente uno de los puntos críticos para construir una metodología de investigación sobre estos temas desde las ciencias de la comunicación-, resulta un dato emergente de diversos análisis la escasa presencia que las personas migrantes tienen «por sí mismas» en los discursos de los medios de comunicación, en relación con la frecuencia y características de las referencias que operan sobre ellas por parte de no migrantes, ya se trate de informantes o de comunicadores/as. Ello nos conduce a pensar en qué condiciones, y con cuáles implicancias, los/as migrantes se convierten en «objetos» de los discursos mediáticos y, con frecuencia, en focos de la producción noticiosa en los diversos géneros de los medios.

Para comenzar a pensar los modos de representación de las personas migrantes en las noticias producidas y difundidas por los medios, corresponde retomar una definición del término noticia: la referencia a un suceso fuera de lo cotidiano, fuera de serie, cuyas características particulares lo hacen especialmente apto para ser contado e incluido en la agenda mediática. De 
esta manera, la noticia nos lleva a pensar en los discursos que recrean lo excepcional -negativo o positivo- en el marco de las agendas periodísticas, políticas y sociales interrelacionadas (Martini, 2015; 2000; Sunkel, 2003; Trew, 1983, entre otros/as). No obstante, el relevamiento de noticias sobre migración o personas migrantes nos permite observar que resulta frecuente un desplazamiento de sentido según el cual lo noticioso se traslada de los hechos o a las acciones hacia quienes los llevan a cabo. Esto no es sólo un mecanismo vinculado con la migración; por el contrario, existe una profusa actividad periodística basada en las notas «de color» o de interés general, que tienden a la visibilización de temas o sucesos que son curiosos o involucran a figuras públicas, así como a desconocidas que son resaltadas por su creatividad, innovación, etc. Sin embargo, los discursos mediáticos que centralizan su relato en el elemento migratorio de un contexto de producción de hechos, o bien focalizan en la condición migrante de sus protagonistas, el desarrollo de la noticia deja a un lado la consideración de los/as migrantes como sujetos de la producción mediática y los cristaliza en el lugar de los objetos (López Talavera, 2012; Granados Martínez, 2006).

La prensa de la región latinoamericana ofrece variados e interesantes ejemplos para ver cómo las elecciones periodísticas permiten configurar un perfil específico de migrante que se destaca por encima del hecho sucedido. Aquí se presentan algunos ejemplos: 
Argentina, Diario masivo, 1/4/2016

ERAN EXTRANJEROS, HICIERON PREGUNTAS Y SE LLEVARON UN TELÉFONO SIN PAGAR

Eran dos, entraron como cualquier cliente y en su apariencia sobresalían su acento extranjero y el color oscuro de su tez. Alguien dijo en el barrio que «eran africanos», pero la víctima luego lo rectificó: «Parecían brasileños».

Perú, Diario masivo, 17/7/2018

\section{DETIENEN A CUBANO Y BOLIVIANO POR SER ILEGALES}

Juliaca. Dos ciudadanos extranjeros, uno de nacionalidad boliviana y otro cubano, fueron detenidos por la policía luego de que incurrieran en el delito contra la Ley de Extranjería, al no contar con el permiso para permanecer en tierras peruanas.

Bolivia, Diario masivo, 9/9/2017

BUSCAN A EXTRANJEROS QUE ABATIERON A POLICÍA ANTIDROGAS EN IXIAMAS

Efectivos de la Policía están tras los pasos de dos extranjeros acusados de ser los autores de la muerte del cabo Reynaldo Espinoza Vargas, integrante del Grupo de Inteligencia y Operaciones Especiales (GIOE) que hizo frente al fuego cruzado con presuntos narcotraficantes en la región de Ixiamas en el norte de La Paz.

Uruguay, diario nacional masivo, 21/4/2018

PRISIÓN PREVENTIVA PARA TRES EXTRANJEROS Y UN URUGUAYO POR VIOLENTO COPAMIENTO A AEROCLUB 
Un brasileño, dos paraguayos y un uruguayo recibieron 180 días de prisión preventiva por los delitos de asociación para delinquir y rapiña.

El brasileño y uno de los paraguayos son pilotos profesionales. Se estima que querían llevarse dos aviones. Fuentes de la Policía dijeron que habían robado combustible para aviones en Colonia. Dos brasileños que integraban el grupo quedaron libres por falta de pruebas.

Tabla 3. Selección y muestreo a manera de ejemplo de titulares y bajadas de noticias gráficas donde se refiere a personas migrantes. Fuente: elaboración propia.

Como podemos ver en la Figura 3, en las noticias policiales son muy frecuentes las referencias a la nacionalidad o a la condición de extranjero/a de una persona involucrada en una noticia. Esto parece formar parte de una forma de construcción de la noticia que emparenta al Otro responsable de una acción incorrecta, con ese Otro construido a través de la migración, el viaje y el desarraigo. Este desplazamiento presenta una relevancia muy acentuada desde los análisis que articulan herramientas de comunicación y derechos humanos, puesto que estudiar la construcción de mensajes periodísticos o mediáticos desde esta combinación conceptual y metodológica implica que se aplique un esquema de análisis del discurso - siguiendo la escuela o combinación de enfoques que se considere pertinente- en el sentido de identificar operaciones simbólicas de prevención o, de lo contrario, promoción de la discriminación, así también para relevar la heterogeneidad de situaciones de recepción del derecho — tanto el de la comunicación como el relacionado con el tema de la noticia: migración, violencia de género, salud, etc.- 
estudiando así cuáles son las producciones mediáticas que contemplan esta dimensión y cuáles la omiten o tergiversan (Lario Bastida, 2006).

\section{Puntapiés metodológicos para un análisis articulado entre comunicación y derechos humanos}

A partir de las reflexiones construidas en la sección anterior, se propone aquí una indagación de ida y vuelta entre aportes de las ciencias de la comunicación y del campo interdisciplinario de los derechos humanos, articulación que se halla crecientemente fortalecida desde los reportes globales sobre migraciones construidos desde las organizaciones internacionales (OIM, 2018; 2017). Tener en cuenta ambos espacios de producción de conocimiento contribuirá a generar análisis multidimensionales y con capacidad de generar incidencia sobre los contextos estudiados, puesto que la perspectiva de derechos implica generar insumos para incidir en desafíos o asignaturas pendientes en materia de acceso.

a. ¿Cómo criticar desde el enfoque de derechos a la objetivación mediática de las personas migrantes en contextos de movilidad?

- Destacar la condición de migrante o extranjero/a de una persona involucrada en la noticia para connotar negativamente esta característica es una acción contraria al ejercicio periodístico desde un enfoque de derechos humanos, cuya normativa de referencia establece que la condición de nacionalidad constituye un motivo expresamente prohibido de discriminación.

- Si se focaliza en la condición de extranjería de una persona para calificar o caracterizar su acción en sociedad, se activa un prejuicio que puede derivar en situaciones de discriminación en las que el Estado tiene una obligación de prevención y de garantía de los grupos potencialmente afectados. 
- $\quad$ Este tipo de construcciones se magnifican a través de los mensajes mediáticos masivos y crean un círculo de retroalimentación entre medios y sociedad que pone en circulación discursos estigmatizantes y sesgados sobre comunidades migrantes, cuyos riesgos pueden ser muy graves (López Talavera, 2012).

b. ¿Cómo potenciar el análisis comunicacional de un discurso mediático prestando atención a los elementos que permiten observar coyunturas específicas de derecho a la comunicación?

El uso de las herramientas del análisis del discurso en sus diversas vertientes (francesa, estructuralista, ideológica, etc.) permite la enumeración de aspectos relevantes para adecuar metodológicamente la mirada respecto de un corpus de discursos armado de acuerdo con objetivos de investigación (Labrin Elgueta, 2009). Por ello, en el momento de delimitar los elementos pertinentes de observación para analizar un discurso mediático sobre migrantes, pueden recomendarse las siguientes pistas:

- El uso del léxico y de los términos específicos para caracterizar a personas, grupos y fenómenos.

La estructura de los razonamientos.

- Las voces que se incorporan en el relato.

La inclusión de fuentes y su uso específico.

- $\quad$ El uso y descripción de estadísticas.

- La referencia a normativas nacionales o internacionales.

En la sinergia entre a) y b), puede afirmarse que un proyecto de indagación organizado desde las ciencias de la comunicación, aunque con abordajes interdisciplinarios como los requeridos para una aplicación del enfoque de 
derechos, requiere de un armado metodológico riguroso, del mismo modo que otras ciencias sociales. La cercanía o el conocimiento previo con los materiales y objetos de estudio no garantiza de por sí el diseño de la investigación ni lo da por hecho. Esto es especialmente relevante cuando se cree conocer las modalidades generales de producción de determinado medio, a partir de la interacción que se ha tenido con éste en carácter de audiencia; por el contrario, el rol de investigación requiere un distanciamiento respecto de esos aprendizajes previos para poder cuestionar esas imágenes 0 asignaciones simbólicas de los medios.

Es posible que un diario considerado progresista o más respetuoso en materia de derechos, desde el punto de vista del consumo cultural, revele importantes falencias en este sentido cuando se le aplica un estudio basado en un diseño metodológico elaborado minuciosamente. Del mismo modo, y sobre todo con las noticias de migración, sería muy posible y frecuente observar continuidades y similitudes entre medios considerados en puntos opuestos del arco ideológico, pero que en materia migratoria adolecen de los mismos errores y prácticas periodísticas desaconsejadas. Es por ello que las conclusiones de un análisis comunicacional no deben abrevar en el sentido común, ni en el rol de quien investiga como parte de las audiencias, sino que deben construirse en el proceso de investigación, para así desactivar clichés y estereotipos sobre los medios en sus más diversas connotaciones (Meccia, 2017; Castiglione, 2012; Halpern, 2007; Amossy y Herschberg Pierrot, 2001).

Para desarrollar un análisis con estas condiciones, se requiere la elaboración de un diseño de investigación que especifique el corpus de análisis y su composición, así también su justificación conceptual y metodológica y los lineamientos espaciotemporales. Es importante señalar que, aunque las 
ciencias de la comunicación sean transdisciplinarias y especialmente adecuadas para el análisis por problemas y no por temas (Matus, 2008), sus objetos de investigación no pueden leerse ni estudiarse sólo desde matrices o modelos tomados de otras disciplinas (sociología, filosofía, ciencias políticas), sino que el camino debe ser inverso: de la comunicación hacia otros campos disciplinares.

\section{Por una re-subjetivación de las personas migrantes en el discurso mediático}

En relación con las aseveraciones de la sección anterior, un análisis de las producciones mediáticas sobre la migración que pueda realizarse desde la comunicación y los derechos humanos puede estructurarse sobre las siguientes premisas de relevamiento y caracterización del material recopilado y organizado en un corpus:

- $\quad$ Para incorporar un enfoque de derechos, una producción mediática debe combinar las fuentes e informantes tradicionales con aquéllos que le permiten forjar una mirada específica desde el paradigma de derechos: instrumentos internacionales, reportes de organizaciones de la sociedad civil y de organizaciones internacionales, uso claro y completo de estadísticas producidas por fuentes confiables, etcétera.

Cuando un medio trabaje con los mismos datos que otros enfoques periodísticos, es posible estudiar y articular los elementos informativos en torno de una producción que ofrezca información y conocimiento sobre el hecho noticiable, y a la vez construya a los protagonistas de su noticia como sujetos de derechos. Estos aspectos pueden ser observados y analizados en una investigación comunicacional con enfoque de derechos. 
- La condición de extranjero/a o migrante puede ser una característica de la persona que se encuentra involucrada en el hecho noticioso, pero no puede tratarse como un rasgo definitorio de su perfil ni de sus acciones, pues ello no tiene sustento desde el plano lógico ni el de investigación.

- En términos de análisis de la información o de la formación de opinión, es riesgoso centrar el peso de la noticia en la nacionalidad de las personas, puesto que ello no brinda datos extra sobre el hecho noticioso en sí pero, sin embargo, coadyuva casi de manera automática a la formación de prejuicios y estereotipos sobre migrantes.

- $\quad$ ¿El hecho noticioso hubiera variado en algo si la persona involucrada no hubiera sido extranjera? ¿Las características de la acción o sus resultados hubieran sido distintos? ¿Hay decisiones implícitas en ese hecho que se relacionan directamente con el origen nacional o con la decisión de migrar? Si la presencia o ausencia de la variable ser migrante o extranjero/a no modifica el curso de los acontecimientos, es justo preguntarse por su incidencia real en el suceso y por su valor informativo concreto.

Reconstruir la mirada sobre las personas migrantes desde una perspectiva de derechos humanos constituye un paso fundamental para reflexionar sobre la práctica periodística que informa y contribuye a formar opiniones en la sociedad. Rescatar el rol social del periodismo como potencial colaborador en las acciones de igualdad y no discriminación frente a colectivos históricamente vulnerabilizados, como es el caso de los grupos migrantes, resulta de gran importancia en la actualidad. Se requiere de investigaciones metodológicas que abreven en el campo de la comunicación y de los derechos humanos de manera articulada y equilibrada, porque el ejercicio periodístico y mediático 
supervisado y acompañado desde el enfoque de derechos humanos contribuye no sólo a generar experiencias más emparentadas con el deber de informar de manera adecuada, suficiente y necesaria, sino también implica contribuir a la formación de sociedades más igualitarias, democráticas y reflexivas. La ausencia, la omisión o la falta de chequeo de información errónea también son falencias periodísticas en derechos humanos. Por lo tanto, tanto el acto de informar como el de (mal)desinformar son prácticas que pueden analizarse desde un enfoque de derechos y permiten la elaboración de resultados de investigación social consistentes para el campo comunicacional. Éstos, a la vez resultan propicios para confeccionar insumos de políticas que permitan ampliar y profundizar la incidencia de los estudios en ciencias de la comunicación, con el fin de discutir y transformar las operaciones simbólicas que condicionan el acceso a derechos en una sociedad, haciendo foco en grupos que requieren especial protección, como es el caso de las personas migrantes.

\section{Bibliografía}

- Abramovich, V. (2006). Una aproximación al enfoque de derechos en las estrategias y políticas de desarrollo. Revista de la CEPAL, № 88, 35-50.

- Amossy, R. y Herschberg Pierrot, A. (2001). Estereotipos y clichés. Buenos Aires, Argentina: Eudeba.

- Castiglione, C. (2012) La cabeza de la hidra y el lugar del sujeto migrante en los medios de comunicación. Voces en el Fénix, Nㅜ 21, 2429.

- Fraiman, W. (2015). Derecho a la comunicación y migrantes: articulaciones normativas y demandas sociales (1980-2009). Question, Vol. 1(48), 341-354. 
- Gottero, L. (2010). Periodismo migrante y construcción de la colectividad paraguaya en Argentina. Una agenda de cuestiones e imaginarios en común. Chasqui, Revista Latinoamericana de Comunicación, № 112, 5963.

- Granados Martínez, A. (2006). Medios de comunicación, opinión y diversidad (social y cultural). Reflexiones en torno al fenómeno migratorio (59-83). En Lario Bastida, M. (Coord.) Medios de comunicación e inmigración. Murcia, España: Convivir sin racismo.

- Halpern, G. (2007) Medios de comunicación y discriminación. Apuntes sobre la década del '90 y algo más. Boletín de la BCN, № 123, 149-173.

- Labrin Elgueta, J. M. (2009). Migración y medios de comunicación: elementos para su análisis desde una perspectiva intercultural. Perspectivas de la Comunicación, Vol. 2(1), 66-74.

- Lario Bastida, M. (Coord.) (2006) Medios de comunicación e inmigración. Murcia, España: Convivir sin racismo.

- Lopez Talavera, M. (2012). La Ética Periodística en el tratamiento informativo de la inmigración. Cuadernos de Información y Comunicación, Vol. 17, 339-354.

- Loreti, D. y Lozano, L. (2015). Prefacio. Voces en el Fénix, Año 6(49), 69.

- Martini, S. (2015). La construcción de la agenda de los medios. El efecto agenda-setting en los medios argentinos en el periodo 2003-2015. Voces en el Fénix, Año 6(49), 96-105.

- Martini, S. (2010). Periodismo, noticia y noticiabilidad. Buenos Aires, Argentina: Norma. 
- Matus, C. (2008), Teoría del juego social, Lanús, Argentina: Ediciones de la UNLa.

- Meccia, E. (2017). No me discuta: Migración reciente en Argentina y medios de comunicación desde el análisis sociológico-lingüístico del discurso. Revista Latinoamericana de Metodología de las Ciencias Sociales, Vol. 7(1), e022.

- Melella, C. (2015). Migraciones latinoamericanas y prensa gráfica. Análisis comparativo entre Argentina y España. En Odisea, Revista de Estudios Migratorios, № 2.

- Naciones Unidas (2006). Preguntas frecuentes sobre el enfoque de derechos humanos en la cooperación para el desarrollo. Ginebra, Suiza: ACNUDH.

- OIM (2018). Informe sobre las migraciones en el mundo. Ginebra, Suiza: OIM.

- OIM (2017). Decálogo para el tratamiento periodístico del tema migratorio. Buenos Aires, Argentina: OIM.

- Organización de los Estados Americanos (2015). Indicadores de progreso para medición de derechos contemplados en el Protocolo de San Salvador. Washington D. C., Estados Unidos: OEA-SEDI.

- Rossi, J. y Moro, J. (2014). Ganar derechos. Lineamientos para implementar políticas públicas basadas en derechos. Buenos Aires, Argentina: IPPDH.

- Sunkel, G. (2003). La prensa sensacionalista y los sectores populares. Buenos Aires, Argentina: Norma. 
- Trew, T. (1983). Lo que dicen los periódicos. En Fowler, Roger; Hodge, Bob; Kress, Gunther; Trew, Tony (Eds.) Lenguaje y control. México DF, México: Fondo de Cultura Económica.

- Uranga, W. (2015). Cuestiones éticas del periodismo. A la luz del principio 6 de la Declaración de Libertad de Expresión de la CIDH. Voces en el Fénix, Año 6(49), 88-95.

\section{Notas}

${ }^{1}$ En simultáneo con las referencias normativas, y en ocasión del nuevo periodo de gobierno iniciado en diciembre de 2019, debe señalarse la necesidad de revertir la fragilización institucional que sufrieron desde el 2015-6 las agencias del Estado especialmente encargadas de proteger los derechos comunicacionales de las audiencias y de dar cuenta del cumplimiento de la normativa vigente.

${ }^{2}$ Una crítica pormenorizada del uso del enfoque de derechos humanos en las políticas y estrategias de desarrollo ha sido elaborada por Víctor Abramovich (2006). 